A Platinum Open Access Journal for Organic Chemistry
Tribute

DOAJ Seal
Arkivoc 2022, part iv, 1-5

\title{
The changing landscape of organic chemistry in Australia
}

\author{
Craig L. Francis
}

Biomedical Synthetic Chemistry Group, CSIRO Manufacturing, Jerry Price Laboratory, Clayton, VIC 3168, Australia

Email: craig.francis@csiro.au

\section{This regional issue of Arkivoc is for "Organic Chemistry in Australia"}

It is my pleasure to preface this Arkivoc special issue "Organic Chemistry in Australia". Colleagues engaged in organic chemistry research across this vast country from Perth to Brisbane and several places in between have contributed papers which provide for readers a flavor of the areas of research being conducted "down under". The assembly of this collection of papers led me to reflect on the changing landscape of organic chemistry in Australia since my time as a student at The University of Adelaide 30 years ago...my goodness...how time flies! Back then, most of the organic chemistry activity in the country was essentially single discipline, carried out in a few, well-endowed, elite universities, and led predominantly by men, with a significant proportion of them British or British-trained partly because Australian universities have only awarded PhD degrees since 1948 and only in significant numbers since the 1960s. ${ }^{1}$ It wasn't until 1996 that the first female Associate Professor and Reader in Chemistry was appointed at the University of Melbourne!

Published on line 09-24-2021 
Today, there are many more universities, courtesy of the so-called "Dawkins revolution", a series of tertiary education reforms instituted by then Education Minister, John Dawkins, during 1987-1991, which included conversion of Colleges of Advanced Education (CAEs) and Institutes of Technology (ITs) into universities plus mergers between universities and CAEs or ITs. ${ }^{2}$

Nowadays, multidisciplinary research and industry collaborations are much more important, and for good reasons. Many important societal challenges - problems in biology and medicine, materials and engineering, energy storage, waste remediation etc. - require input from chemistry as a core science, which has led to these multidisciplinary areas flourishing. The trend towards multidisciplinary science has been well described by Strumsky, Lobo, and Tainter, who noted that individual scientific fields undergo a common evolutionary pattern. Early research "plucks the lowest hanging fruit" - the questions that are least costly to resolve and most broadly useful - but gradually the productivity of innovation results in diminishing returns, because as pioneering research depletes the stock of broadly applicable questions, research must progress to more specialized questions that are more difficult and expensive to resolve. Consequently, research organization moves from isolated scientists in single disciplines doing all aspects of a project to teams of scientists and technicians, from multiple disciplines, and various support staff, including administrators and accountants. $^{3}$

In recent years, in an environment of very limited research funding, multidisciplinary projects involving organic chemistry have been strongly prioritized for support/funding, while more fundamental organic chemistry projects, even from universities, have struggled to attract support. ${ }^{4}$ The best multidisciplinary collaborations result from two or more healthy, "cutting edge" disciplines effectively working together. A low level of support for fundamental organic chemistry in favor of predominant support for multidisciplinary research might result in slowed progress towards new discoveries and advances in organic chemistry and creates a risk that the quality of the contributions organic chemists can make to collaborations will be poorer than might otherwise be the case. It may also lead to organic chemistry being viewed as a contractor/service role in collaborative research... a situation I have experienced on several occasions. A counter argument might be that pure fundamental organic chemistry research can meander into curiosities that make no practical advances in the field, whereas multidisciplinary projects can force new ways of thinking and identification of new problems that curiosity-driven research might not have uncovered. The challenge is to find an appropriately balanced portfolio!

We must remember that basic research, driven by curiosity, freedom and imagination, provides the groundwork for all applied research and technology. Curiosity-driven research has afforded truly revolutionary transformations, such as the rapid growth of computer-based intelligence, the discovery of the genetic basis of life, the Google search algorithm, and Einstein's theory of relativity which is used every day in our GPS devices. ${ }^{5}$ While it is understandable that governments are increasingly directing research funding to tackle important societal challenges, this is occurring within flat or decreasing budget envelopes, so we must guard against research becoming dangerously skewed toward short-term goals that may address current problems but miss out on huge advances in the long term. ${ }^{5}$

During my own research career at CSIRO, a large proportion of my time has been spent on collaborative projects (often with industrial partners) involving biologists, some of whom have commented on their perception that "organic chemistry is a mature science", a view I found interesting. While organic chemistry may be around 200 years old with a wealth of tools and understanding, there is still much that remains to be done! Two important topics related to my own research areas that come to mind are safer, more efficient, environmentally benign, "green" synthetic processes, reflected in the rapid growth of research in continuous flow chemistry, and a more systematic, diverse, and efficient exploration of new chemical space, 
exemplified by the increasing use of fragment-based drug discovery techniques. On the latter topic, it is widely accepted that the historical exploration of chemical space by synthetic chemists has been very unsystematic and that the number of core molecular structures in drugs and bioactive space is currently very small and distributed in sparsely populated "islands". ${ }^{6}$ Indeed, around half of all known compounds are based on just $0.25 \%$ of the known molecular scaffolds. ${ }^{7}$

Australia does not have local, large, pharmaceutical or agrochemical companies to provide substantial research funding for organic chemistry, and the local biotech sector, while healthy, is mostly populated by small to medium-sized companies with limited cashflow to use for external research collaborations, so government schemes are a major source of funding. Another consequence of the "Dawkins Revolution" is the increased use, by government funding agencies, of various, supposedly objective, metrics to assess and rate research proposals and output; however, this situation is not unique to Australia. At present, commonly used forms of such metrics are the "h-index" of individual scientists and the "impact factor" of journals in which research is published. Many in the research community consider these metrics as inappropriate and inadequate measures of research quality ${ }^{8-12}$ and a scourge of the profession.

Anecdotally, the paucity and insecurity of funding for organic chemistry researchers in Australia has resulted in an ultra-competitive and less collegial research environment. It has certainly resulted in a dearth of secure employment in this research field. This situation has led to many talented, young scientists leaving organic chemistry research and taking up positions as patent attorneys, sales representatives at scientific equipment companies, high school teachers, or even leaving science completely. It could be argued that having highly trained scientists in such roles is a positive thing, but not if the individuals concerned would rather be researchers, and more importantly, the loss of these talented young scientific minds to other employment means that some ground-breaking discoveries are simply not made.

In my view, upon consideration of the issues and arguments touched on above, a calibrated and balanced system providing adequate levels of funding support to both multi-disciplinary science and fundamental organic chemistry will enable Australian organic chemistry research to thrive in the future. As an enthusiastic synthetic organic chemist, I think that there must remain a place for fundamental organic chemistry endeavor (at least within our universities), such as natural product synthesis, which fosters developments in new synthesis methodology, and the creative art of synthesizing novel molecular structures and templates to provide scaffolds and building blocks for exploration of uncharted chemical space, thus providing opportunities to identify new drugs or other valuable materials, free of patent competition.

In a much more multicultural present-day Australia, there is a significantly increased diversity among those engaging in and leading organic chemistry research. However, the achievement of true diversity in the profession is still a long way off, ${ }^{13,14}$ as you may have noted from the names of the authors on the papers included in this issue, despite my efforts in sending out $>1 / 3$ of invitation letters to women and around one in seven letters to chemists of various Asian backgrounds or origins. While targets and quotas will assist, cultural change is required to establish a more inclusive environment and create a more collegial, collaborative, and successful professional community. ${ }^{13}$ There are some encouraging signs; for example, The University of Sydney has established the National Centre for Cultural Competence, one of the first universities in the world to address cultural competence at a whole-university level ${ }^{14,15}$ and the Royal Australian Chemical Institute (RACI), the key association advocating for the professional interests and activities of chemical scientists across Australia, has imposed diversity targets at RACl-sponsored events and conferences. Recent data show that, in general, the number of women offered plenary and invited speaker roles is equal to or higher than their representation in the delegate group. ${ }^{13}$ Although not directly related to organic chemistry, in my own organization, CSIRO, after many years of an overwhelming majority of male senior managers, I have seen a 
growth in the number of women in leadership roles, including the first female CEO in 2009. The current Chief Scientist of Australia, Cathy Foley, was previously the CSIRO Chief Scientist and in my business unit "Manufacturing", currently all four of the Research Program Directors are women. By building on this progress, we can access the perspectives of and harness the skills and brain power of a more diverse community of scientists, which will lead to greater innovation, increased creativity, faster problem-solving, and better decision making. ${ }^{16,17}$

Enjoy reading the collection of papers in this special 2022 Arkivoc issue, "Organic Chemistry in Australia".

\section{Acknowledgements}

I warmly thank my CSIRO colleagues Drs Paul Savage, Kathleen Turner, and Melissa Skidmore for helpful and stimulating discussions on the topics mentioned in this Introductory article.

\section{References}

1. Dobson, I. R. Australian Universities' Review 2012, 54(1), 94-101.

https://files.eric.ed.gov/fulltext/EJ968535.pdf

2. "Higher education: a policy statement. National Library of Australia". https://nla.gov.au/nla.obj2518053881/view?partld=nla.obj-2520348041\#page/n48/mode/1up (retrieved 2 August 2021).

3. Strumsky, D.; Lobo, J.; Tainter, J. A. Syst. Res. 2010, 27, 496-509. https://doi.org/10.1002/sres.1057

4. Over the period 2009-2020, success rates for the Australian Research Council "Discovery Projects" grants (the main scheme for fundamental research) have been in the range $18-23 \%$. See https://www.arc.gov.au/news-publications/media/presentations/standard-arc-schemes (retrieved 2 August 2021).

5. Dijkgraaf, R. Curiosity-Driven Knowledge Is a Vital Form of Infrastructure. 2017. https://www.scientificamerican.com/article/curiosity-driven-knowledge-is-a-vital-form-ofinfrastructure/ (retrieved 5 August 2021).

6. Taylor, R. D.; MacCoss, M.; Lawson, A. G. D. J. Med. Chem. 2014, 57, 5845-5859. http://dx.doi.org/10.1021/jm4017625

7. Dow, M.; Fisher, M.; James, T.; Marchetti, F.; Nelson, A. Org. Biomol. Chem. 2012, 10, 17-28. http://dx.doi.org/10.1039/C10B06098H

8. Koltun, V.; Hafner, D. The h-index is no longer an effective correlate of scientific reputation. PLOS ONE 2021, 16(6), e0253397. https://doi.org/10.1371/journal.pone.0253397

9. De Rijcke, S.; Waltman, L.; van Leeuwen, T. Halt the h-index. 2021. https://www.leidenmadtrics.nl/articles/halt-the-h-index (retrieved 4 August 2021).

10. Paulus, F. M.; Cruz, N.; Krach, S. The Impact Factor Fallacy. Front. Psychol. 2018, 9, 1487. https://doi.org/10.3389/fpsyg.2018.01487

11. Gingras, Y.; Khelfaoui, M. Why the h-index is a bogus measure of academic impact. 2020. https://theconversation.com/why-the-h-index-is-a-bogus-measure-of-academic-impact-141684 (retrieved 5 August 2021). 
12. Chapman, C. A.; Bicca-Marques, J. C.; Calvignac-Spencer, S.; Fan, P.; Fashing, P. J.; Gogarten, J.; Guo, S.; Hemingway, C. A.; Leendertz, F.; Li, B.; Matsuda, I.; Hou, R.; Serio-Silva, J. C.; Stenseth, N. C. Proc. R. Soc. B. 2019, 286, 20192047. http://dx.doi.org/10.1098/rspb.2019.2047

13. Schultz, M.; Coote, M.; Bissember, A. RACl inclusion and diversity: a report on progress. 2019. https://chemaust.raci.org.au/article/mayjune-2019/raci-inclusion-and-diversity-report-progress.html (retrieved 2 August 2021).

14. Mehta, G.; Yam, V. W. W.; Krief, A.; Hopf, H.; Matlin, S. A. Angew. Chem. Int. Ed. 2018, 57, $14690-$ 14698. https://doi.org/10.1002/anie.201802038

15. The University of Sydney, National Centre for Cultural Competence website https://www.sydney.edu.au/nccc/ (retrieved 3 August 2021).

16. Antonio, A. L.; Chang, M. J.; Hakuta, K.; Kenny, D. A.; Levin, S.; Milem, J.F. Psychological Science, 2004, 15(8), 507-510. https://doi.org/10.1111/j.0956-7976.2004.00710.x

17. Gibbs, K.D.; Han, A.; Lun, J. Ch. 15. Demographic Diversity in Teams: The Challenges, Benefits, and Management Strategies. In Strategies for Team Science Success; Hall, K.; Vogel, A.; Croyle, R. (Eds) Springer; Cham, 2019; pp 197-205. https://doi.org/10.1007/978-3-030-20992-6 15 